\title{
Anti-poverty Path Analysis of Closely Grouped Extremely Poor Areas Zhenzhen Peng ${ }^{1, a}$ Ji Ma ${ }^{2, b}$ \\ ${ }^{1}$ Department of Economics and Management, Shaoyang University, Shaoyang, Hunan, China, 422100
}

Keywords: New Developmentism, Anti-poverty Path Analysis, Closely Grouped Extremely Poor Areas

\begin{abstract}
With the gradual development of Chinese economy, poverty areas show the contiguous characteristics. According to previous studies, the new developmentist view can better guide the development of the current closely grouped extremely poor areas. In order to better manage the current regional peace problem, we can promote the economic development of the troubled areas as a whole. As the poverty characteristics of contiguous areas show fragile intertwined, specifically the internal and external factors are intertwined, and constantly weaken the level of local economic development. In the current development process, we can continuously build in line with the actual situation of anti-poverty path by taking a continuous or scalable way. In order to better promote the simultaneous development of the economy, we can reduce the vulnerability and explore the anti-poverty path scheme that is in line with the actual situation.
\end{abstract}

\section{Introduction}

With the problem of poverty in Chinese contiguous areas gradually, the new stage of poverty alleviation tasks are gradually put on the agenda. As a result of the tendency of poverty alleviation path, a series of theories have been proposed. However, with the gradual development of the current developmentist point of view, more scholars believe that the poverty-stricken areas in the area of poverty alleviation, through the implementation of large-scale, homogenization of poverty alleviation path, to maximize the governance of the current poverty problem. But there is a question behind the current view that there is a logical consistency between the progressive development of the current economy and the governance of poverty in successive regions. This article through continuous exploration of various governance path, and constantly promote the current governance system.

\section{Theory Overview of the of Anti - poverty Path in Closely Grouped Extremely Poor Areas}

With the current study of the path of anti-poverty, various anti-poverty ideas have been put on the agenda. One of the most influential is the theory of developmentism. The theory mainly focuses on the development of the current nation-state, taking economic growth as the core. Through the use of cross-development approach, and constantly promote the development of the country as a whole. The theory of the specific content mainly includes the following aspects:

The Connotation of the Theory of Developmentism. Developmentism as the main theory of social progress, the theory of national development as the theme, continue to promote the current economic growth. In order to better promote the current economic growth, through the way of economic assistance to optimize the current regional industrial structure, to achieve economic growth to benefit the current population. In order to better promote the current theory of the promotion, can promote the overall economic and cultural progress, and promote the development of new and diverse.

The Specific Content of the Developmentism Theory. According to the current developmentist theory of the actual situation, and constantly promote the theory of the upgrade. (1) The concept of developmentism is mainly aimed at the Western central theory, in the current development process, through continuous optimization of various development methods, sublimation of the current historical and cultural traditions, according to the current actual situation, Innovate the current path 
of development. (2) Under the interaction of various development currents, if we can promote the current economic growth, we can constantly optimize the structure of economic development and integrate the development of industrial economy into the current cultural activities, which is the central idea of economic development.

The Approach of Developmentist Anti-Poverty Path. According to the actual situation of the current economic development, contiguous poverty is a current anomaly, which is different from the current poverty, backwardness and low quality. In order to better promote the current economic development, the Government began to take the way of blood transfusion transformation. On this basis, developmentism can continue to use the method of multiple transformation and gradually promote the current economic and social progress. At present, it is necessary to follow up if the government's policy of poverty alleviation is better promoted, including the road of economic development in the troubled areas. In the current development process, through the continuous promotion of the current economic development, use multiple ways of thinking to promote the economic growth in contiguous areas. According to the current thinking of the theory of developmentism, we can see that in the process of dealing with anti-poverty, we need to continue to promote the process of governance on the basis of protecting the ecological environment.

\section{The Poverty Situation in the Closely Grouped Extremely Poor Areas}

Livelihoods Are Lagging Behind. Based on an understanding of the actual situation of the troubled areas, the poverty situation in the current household income is estimated if it cannot assess the current poverty situation, including the various circumstances related to livelihoods. According to the relevant scholars of the past, we can see that the basic connotation of livelihood is the way of life, but also the whole system of the current action, and thus maintain the current living conditions. Livelihoods mainly refer to the improvement of their living conditions, including the evolution of sustainable concepts, in order to better improve their current livelihoods. Schoologist and the UK National Development Agency believe that sustainable development is the impact of the current response to various pressures, including their own consumption on the basis of continuous improvement of their own ability and capital. On the basis of the current analysis, the current livelihood framework can be constructed, which includes five aspects: (1) Vulnerability background; (2) Asset status; (3) External shock; (4) Livelihood activities; (5) livelihood strategy and other five key links.

Lack of Social Capital. According to the investigation of the situation in poor areas, in this region, its various social capital are in a state of lack of. On the basis of the current, all kinds of natural disasters will affect the production and life. On the basis of the current industry, natural capital, material capital, financial capital, human capital and social capital are collectively referred to as livelihood capital. According to the study of social capital, we can see that social capital can transform each other, and on this basis can improve the ability of family and individual to deal with the risk. When we talk about the ability to deal with risk in the troubled areas, we will find that social resources are often lacking behind poverty. If you can better improve the living standards and increase the use of natural resources, you can maximize its various social status and economic income.

Feasible Capacity Is Low. With the study of the current troubled areas, it is clear that poverty includes income poverty, poverty, poverty, etc., which is concerned with the low availability of various livelihood capital in the current situation, which includes a variety of feasible Sex reduction. In the current livelihood situation, the reason for the low viability is due to the lack of deep means. In the current situation of extremely rich living standards, if you cannot improve the various viability includes the perception of the current livelihood situation, in the current actual situation, and continuously improve the comprehensive utilization of its resources. In order to better improve the current sustainability, the ability to maintain a family situation can be continuously improved to maximize its viability. 


\section{The Anti - Poverty Path of Closely Grouped Extremely Poor Areas}

Even in the current situation of various development cannot better solve the problem in the current poor areas. In order to better address the various poverty problems in the current poor areas, we can maintain the current social equilibrium as much as possible. In order to change the current state of the closed state, you can continue to open the socio-economic system. In short, in order to better promote the current level of economic development in poverty-stricken areas, we can explore the anti-poverty path of the troubled areas from a multiple perspective.

Ecological Perspective. In the current contiguous areas of poverty-stricken areas of anti-poverty path, you can introduce economic geography point of view. This article through the ecological perspective, and constantly promote the current anti-poverty measures to promote. According to the current economic situation, the special situation of anti-poverty areas is through continuous improvement of soil nutrient status, including the optimization of various soil structures. In poor areas, due to the low land production capacity, to a certain extent, will affect its economic development level. Poor areas often have poor environmental characteristics, including the current frequent development of heavy rain road on this basis continue to promote the current loss of soil organic matter. From the ecological perspective of the way, continue to promote the low labor quality. In the current ecological perspective, increasing the current population capacity, continuously improve the population capacity, in order to increase the poverty-stricken areas of anti-poverty capacity. In short, the way of anti-poverty among eco-poor scholars is to change the living space and the specific measures are to improve land quality, immigration and population control. Specifically, in the current situation, continuously improve the soil quality, the maximum realization of soil value.

Humanity Perspective. According to the current research on the troubled areas, the poverty situation in the region has experienced poverty from poverty to poverty and poverty. According to the current development situation, income poverty mainly refers to the lack of people's daily living material. Poverty is mainly due to the lack of information on people's access to life. Right poverty refers mainly to the differences in political and cultural rights enjoyed by members of society. Right poverty mainly refers to the current social members cannot get effective protection. The United Nations organizations believe that capacity development is a denial of the current state of development. In the current definition of poverty, the various types of poverty have mutual homology, including income poverty, ability poverty, rights and poverty intertwined, complementary and interactive, rather than alone isolated situation. In order to better integrate the current relationship between man and society, to express its overall situation. Therefore, in the humanistic perspective, poverty not only means the backwardness of productivity, but also includes the current lack of development capacity, including the perception of a particular historical and cultural. In short, poverty arises in the interaction between man and nature and society.

Fusion Perspective. With the current economic and cultural development, in dealing with anti-poverty issues, we need to integrate the current natural ecology and cultural and cultural perspective.

Researchers believe that in the solution to the problem of poverty, the need to constantly integrate the current development, in particular, with the natural and social interaction between the interaction and the poor areas of people.

The poverty is often converged. Especially in poor areas, where fragility interacts, interacts with each other, forms an intertwined state, restricting current regional development, including strengthening poverty in the current region. The intertwining of vulnerability can provide a convenient way for the current development, and on this basis, the integration of natural, economic and social factors.

\section{The Anti-Poverty Path Measures in Closely Grouped Extremely Poor Areas}

Maintain the Sustainability of Ecosystems. According to the actual situation of the current troubled areas, the ecological sustainability can be promoted by maintaining the overall 
sustainability. According to previous studies, the current ecological balance is a benign union of socio-economic-natural complex ecosystems, including innovation of anti-poverty path in contiguous areas. In this process of anti-poverty, it can continue to promote the optimization and upgrading of livelihoods.

Due to the current development situation, continue to promote the upgrading of various capabilities. In this process, there is an anti-fragile development, including the current direction of the various development. In order to better reduce the risk, improve the level of response, including the development of various decisions and actions. According to the current development, we can continue to focus on the future direction of development, including the development of the current vulnerability, and constantly promote the current regional development. According to the current development, and constantly improve the current sustainable development.

Maintain the Development of Cultural Background. According to the current economic and cultural development, and constantly promote the myth of the path of poverty. In poverty-stricken areas, vulnerability is a result of common development in humanistic conditions, environmental conditions and variability. In these interactive factors, continue to promote the current disease, unemployment, economic crisis development. In the current cultural context, the current system structure is continually optimized, including the promotion of vulnerability standards, including individual, family, collective and public sector development. In the current cultural background, and constantly improve the cost of various types of livelihood. In the current livelihood, the maximum optimization of the structure, improve the various systems, including in a variety of resources in the construction process, to promote the corresponding policy to be improved. The transformation of structure and system mainly refers to the improvement of various levels of development, including capital exchange, by improving various construction capabilities.

\section{Conclusion}

According to the current development characteristics of the regional contiguous areas, constantly improve the relationship between the current family environment and the population situation to enhance the anti-poverty ability in the troubled areas. In this process of anti-poverty, according to the current situation, we can maximize the promotion of its diversified development, including the anti- poverty understanding process of contiguous areas and constantly promote the current social, economic, natural and other diversified development process. In this process, it includes the construction of complex ecosystems, which is consistent with the current constructivist view. Therefore, the new developmentism as an effective cycle mechanism, it can maximize the maintenance of current structure, which is the current core elements. According to the current development process, continue to maintain the current core interests, maximize the elimination of the current gap and improve the current development level.

\section{References}

[1] Research on the Coupling Relationship between Farmers' Livelihoods and Ecosystem Services [J] .Fu Bin, Wang Yukuan, Xu Pei, Yan Kun. Ecological Economy. 2017 (01)

[2] A comparative study on the livelihood capital of the affected farmer and the undeveloped farmer - based on the investigation of the Yichang area [J]. GAO Hong, RUAN Kangliang, CHEN Min. Journal of Hubei Institute for Nationalities (Philosophy and Social Sciences) .2016 (6): 96 -98.

[3] An evaluation of sustainable livelihood safety and its robustness in Qinba Mountain area of southern Shaanxi [J] .She Yuzhong, Yang Xinjun, Wang Ting. Geographical Research. 2016 (12): 56-58.

[4] Informal Insurance System and Farmers' Risk Sharing Modeling and Policy Implications Empirical Study from CFPS Data [J]. Wang Xiaoquan, Luo Ditao, Wang Qi. Economic Science. 2016 (6): 136-139. 
[5] Empirical Study on the Effect of Relocation of Poverty Alleviation on Farmers' Poverty Reduction - Based on the Survey of Farmers in the Central Soviet Area of Southern Jiangxi Province [J]. Chen Shengdong, Cai Jingyuan, Liao Wenmei. Journal of Agroforestry. 2016 (6): 121-123.

[6] Ecological compensation on the impact of household livelihoods [J]. Pang Wen, Wang Chengchao. Rural Economy and Science and Technology. 2016 (23): 125-126.

[7] Analysis of the livelihood status of farmers in typical mountainous areas of western China - A case study of Baoxing County in Sichuan Province [J]. Liu Ju, Fu Bin, Wang Yukuan, Xu Pei. Journal of China Agricultural University. 2016 (12): 89-91. 